КРУПНОМАСШТАБНЫЕ ДЫМКИ ЕВРАЗИИ ЛЕТОМ 2016 г. () 2019 г. Г. И. Горчаков ${ }^{1}$, С. А. Ситнов ${ }^{1}$, А. В. Карпов ${ }^{1}$, И. А. Горчакова ${ }^{1}$,

\author{
Р. А. Гущин ${ }^{1,2}$, О. И. Даценко ${ }^{1,2}$ \\ ${ }^{1}$ Институт физики атмосферы им. А.М. Обухова РАН \\ 109017, Москва, Пыжевский пер., 3 \\ ${ }^{2}$ МИРЭА-Московский Технологический университет \\ 119454, Москва, Проспект Вернадского, 78 \\ e-mail: gengor@ifaran.ru \\ Поступила в редакцию 31.07.2018 г. \\ Принята к печати 28.11.2018 г.
}

\begin{abstract}
Оценены масштабы распространения оптически плотных дымок на территории Евразии в период с 15 по 31 июля 2016 г. (20 млн км²), включая рекордную по масштабам сибирскую дымную мглу (СДМ) - примерно 16 млн км², смог на Северной Китайской Равнине (около 2 млн км²), включая прилегающие морские акватории, пыльную мглу в районе пустыни Такла-Макан (около 0.8 млн км²) и дымки на территории Индии и Пакистана (примерно 1 млн км²). Использована методика построения пространственного распределения максимальных значений аэрозольной оптической толщины (МАОТ). Эмпирическая функция распределения (ЭФР) МАОТ аппроксимируется линейной функцией логарифма МАОТ. Проанализировано пространственное распределение аэрозольной оптической толщины (АОТ) на длине волны 550 нм в СДМ. Получены оценки суммарной массы дымового аэрозоля (ДА) в СДМ (3.2 млн т), в том числе на территории Сибири $\left(50^{\circ}-70^{\circ} \mathrm{N}\right.$, $60^{\circ}-120^{\circ} \mathrm{E}$ ), в период максимального задымления с 22.07 по 26.07.2016 (примерно 2 млн т). Изменения качественного состава ДА в СДМ в процессе его переноса проиллюстрированы пространственной и временной изменчивостью аэрозольного индекса (АИ). Показано, что вариации АИ происходят согласованно с вариациями АОТ. Оценены аэрозольные радиационные форсинги (АРФ) на верхней и нижней границах атмосферы на территории Сибири в период 22.07-26.07.2016 (средние АРФ составляли -67 и -98 Вт/м²). ЭФР АОТ и АРФ на верхней границе атмосферы аппроксимированы экспоненциальной и степенной функциями АОТ соответственно.
\end{abstract}

\begin{abstract}
Ключевые слова: крупномасштабные оптически плотные дымки, методика диагностики плотных дымок, дальний перенос, сибирская дымная мгла, массовые лесные пожары, активные очаги пожаров, радиационная мощность пожаров, дымовой аэрозоль, аэрозольная оптическая толщина, эмпирическая функция распределения, масса дыма, аэрозольный индекс, аэрозольный радиационный форсинг, MODIS, AERONET.
\end{abstract}

DOI: https://doi.org/10.31857/S0002-351555341-51

\section{ВВЕДЕНИЕ}

В настоящее время много внимания уделяется исследованиям свойств и состава атмосферы при крупномасштабных задымлениях [1-9]. Для теории климата большой интерес представляют радиационные эффекты дымового аэрозоля (ДА) [10-13], включая влияние крупномасштабных задымлений на перенос инфракрасной (тепловой) радиации [14]. При крупномасштабных задымлениях на больших территориях заметно ухудшается экологическая обстановка [15-18] и существенно меняется газовый и аэрозольный состав атмосферного воздуха [19-22], а также протекающие в атмосфере фотохимические процессы [23-25]. В частно- сти, благодаря фотохимической трансформации летучих и полулетучих органических соединений изменяются размеры и состав частиц аэрозоля («старение» дымового аэрозоля) [26-28].

Летом 2016 г. на европейской части России и прилегающих территориях наблюдалось крупномасштабное задымление, обусловленное аномальным восточным переносом задымленных воздушных масс из регионов Сибири, охваченных массовыми лесными пожарами [29, 30]. В работах [31, 32] были проанализированы радиационные эффекты ДА над Европейской частью России (ЕЧР) и Белоруссией в июле 2016 г. Однако масштабы задымления Евразии в целом и радиационные эффекты в Сибири не рассматривались. 
Кроме распространившейся на рекордную по площади территорию сибирской дымной мглы (СДМ) 2016 г. в Евразии наблюдались и другие оптически плотные дымки, включая смоги на Северной Китайской Равнине (СКР), пыльная мгла в районе пустыни Такла-Макан и плотные дымки на территории Индии и Пакистана. Максимального развития замутненность атмосферы над Евразией достигла во второй половине июля 2016 г.

Целью настоящей работы является оценка пространственных масштабов плотных дымок и вариаций аэрозольной оптической толщины (АОТ) в период с 15 по 31 июля 2016 г. Для оценки масштабов распространения плотных дымок предложено использовать пространственное распределение максимальных значений аэрозольной оптической толщины (МАОТ). Изменчивость МАОТ охарактеризована эмпирической функцией распределения (ЭФР) по частотам повторяемости ее логарифма. По данным мониторинга с помощью установленных на спутниках Terra и Aqua спектрометров MODIS получено пространственное распределение АОТ на длине волны 550 нм для СДМ на территории Евразии и на территории Сибири в период близкого к максимальному задымления с 22 по 26 июля 2016 г., что позволило оценить суммарную массу дыма для СДМ, статистические характеристики вариаций АОТ и аэрозольные распределения форсинга для коротковолновой солнечной радиации на верхней и нижней границах задымленной атмосферы. Получен временной ход средних АОТ на занятой СДМ территории Евразии летом 2016 г. Выполнено сопоставление масштабов задымления Сибири с уровнем замутнения СКР плотной дымкой (смогом) в период с 27 по 31 июля 2016 г.

Пространственное распределение аэрозольного индекса (АИ), полученного с помощью установленного на спутнике Aura спектрометра OMI, позволяют охарактеризовать качественные изменения состава дымового и фонового аэрозоля в период с 15 по 31 июля и временную изменчивость АИ летом 2016 г. на территории, ограниченной координатами $40^{\circ}-70^{\circ} \mathrm{N}$ и $0^{\circ}-140^{\circ}$ Е. В работе представлено пространственное распределение активных очагов горения (MODIS/Terra) с индикацией радиационной мощности пожаров (РМП) в период с 15 по 31 июля 2016 г. и показаны временные изменения суммарного количества пожарных пикселей (КПП) летом 2016 г. на территории от $40^{\circ}$ до $70^{\circ} \mathrm{N}$ и от $0^{\circ}$ до $140^{\circ} \mathrm{E}$.

\section{АНАЛИЗИРУЕМЫЕ ДАННЫЕ}

В работе использовались данные мониторинга АОТ на длине волны 550 нм спектрорадиометрами MODIS (V6), установленными на спутниках Aqua и Terra [33], полученные с пространственным разрешением $1^{\circ} \times 1^{\circ}$ (L3) с помощью системы анализа и визуализации данных Giovanni (https://giovanni.gsfc.nasa.gov/ giovanni) [34].

Анализировались данные об очагах пожаров (https://earthdata.nasa.gov) на территории Евразии, полученные с помощью спектрорадиометра MODIS/Terra (C6, L2) с пространственным разрешением 1 км $\times 1$ км [35], а также данные мониторинга АИ с помощью установленного на спутнике Aura спектрометра OMI (пространственное разрешение 1 км $\times 1$ км) $[36,37]$.

С целью оценки применимости радиационной модели ИФА $[10,13]$ использовались данные мониторинга (L1.5) оптических и микрофизических характеристик ДА на размещенных в Евразии станциях AERONET [38].

\section{ПРОСТРАНСТВЕННОЕ \\ РАСПРЕДЕЛЕНИЕ КРУПНОМАСШТАБНЫХ ДЫМОК В ИЮЛЕ 2016 г.}

Оптически плотные дымки, включая дымную мглу, смоги и пылевые выносы радикально меняют радиационный режим атмосферы. Образующаяся при горении биомассы дымная мгла является важным климатическим фактором. Поэтому несомненный интерес представляет оценка масштабов задымления, возникающих при массовых лесных пожарах, а также масштабов повышенных замутнений атмосферы дымками других типов.

В июле 2016 г. на значительную часть территории Евразии распространилась возникшая в Сибири дымная мгла [29, 30, 39]. Масштабы задымления ЕЧР в этот период были оценены в работах [31, 32]. На примере дымной мглы, образовавшейся летом 2010 г. на ЕЧР, было показано $[11,40]$, что в дымной мгле происходит сложная эволюция пространственного распределения ДА, существенно затрудняющая описание этого процесса. В связи с этим для характеристики распространения дымной мглы и других типов оптически плотных дымок предложено использовать пространственное распределение МАОТ за определенный период времени. 
Дымная мгла на ЕЧР была обнаружена 24 июля 2016 г. [29, 32]. Последующий анализ данных спутникового мониторинга АОТ показал, что во второй половине июля 2016 г. была задымлена значительная часть территории Евразии. Об этом свидетельствует пространственное распределение MAOT или $\tau_{\max }$ (MODIS/Aqua) на длине волны 550 нм с пространственным разрешением $1^{\circ} \times 1^{\circ}$ (L3) в период с 15 по 31 июля 2016 г. на территории, ограниченной координатами $25^{\circ}-75^{\circ} \mathrm{N}$ и $0^{\circ}-140^{\circ} \mathrm{E}$ (рис. 1$)$. Из рисунка следует, что СДМ во второй половине июля 2016 г. занимала большую часть Сибири, практически полностью накрыла ЕЧР и распространилась на многие страны Европы (до Финляндии на севере, Болгарии на юге и Германии на западе), а также на Казахстан и страны Средней Азии. Используемая на рис. 1 шкала МАОТ позволяет наглядно представить пространственное распределение АОТ в СДМ. Отчетливо выделяются охваченные массовыми пожарами регионы Сибири с МАОТ > 3.2. Над значительной частью территории ЕЧР наблюдались плотные дымки (МАОТ > 0.8). В последующих разделах данной работы будут проанализированы не только вариации МАОТ (рис. 2), но и наблюдавшиеся вариации АОТ на длине волны 550 нм (рис. 3-5).

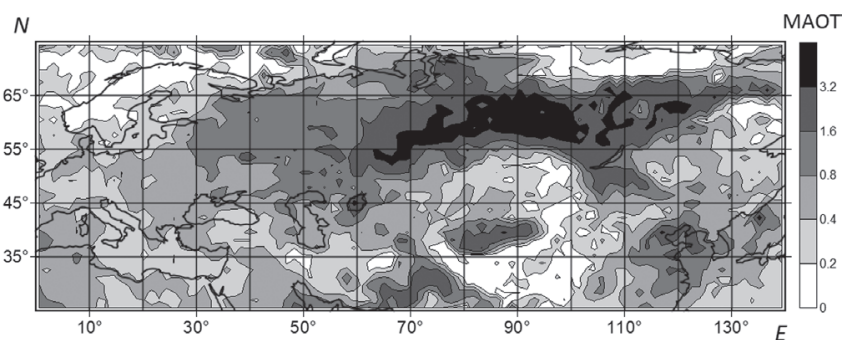

Рис. 1. Пространственное распределение максимальных значений аэрозольной оптической толщины для длины волны 550 нм в период с 15 по 31 июля 2016 г.

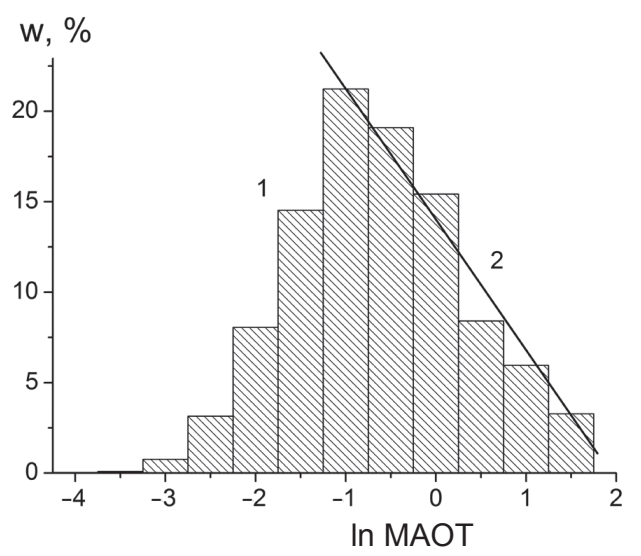

Рис. 2. Эмпирическая функция распределения (1) максимальных значений аэрозольной оптической толщины и ее аппроксимация (2) для МАОТ >0.3.
Область МАОТ $>3.2$ и область распространения интенсивных лесных пожаров (рис. 3а) с радиационной мощностью больше 1000 МВт в основном пересекаются. Многочисленные пожары с малой радиационной мощностью (рис 3в) и, следовательно, с небольшими интенсивностями эмиссий в Причерноморье не привели к заметному задымлению Европейского континента, в том числе, благодаря ярко выраженному восточному переносу воздушных масс в рассматриваемый период [29-32]. Детальная характеристика лесных пожаров необходима для оценки эмиссий газовых примесей и аэрозоля [41]. Наблюдаемые несоответствия МАОТ и РМП могут быть обусловлены атмосферной циркуляцией воздушных масс и эволюцией («старением») дымового аэрозоля [26].

Расчеты показали, что площадь, занятая СДМ в указанный выше период времени с МАОТ $>0.4$, составляла 16.3 млн км². Кроме СДМ в период с 15 по 31 июля 2016 г. на территории Евразии оптически плотные дымки (смоги) наблюдались на СКР $\left(25^{\circ}-45^{\circ} \mathrm{N}\right.$, $110^{\circ}-130^{\circ}$ Е). Площадь распространения смогов достигала примерно 2 млн км².
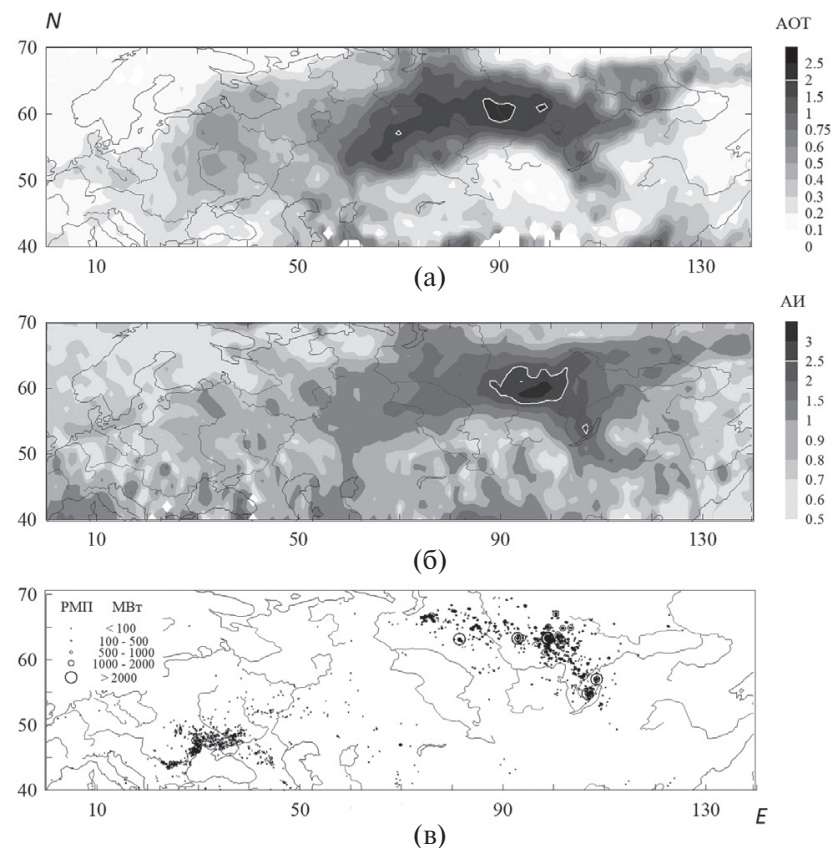

Рис. 3. Пространственные распределения на территории $40^{\circ}-70^{\circ} \mathrm{N}, 0^{\circ}-140^{\circ}$ Е в период 15-31 июля 2016 г.: аэрозольной оптической толщины на длине волны 550 нм по данным спутникого спектрорадиометра MODIS/Terra (a); аэрозольного индекса (АИ) по данным спутникого спектрометра OMI/Aura (б); активных очагов горения по данным MODIS/Terra c индикацией радиационной мощности пожаров (РМП) (в). 

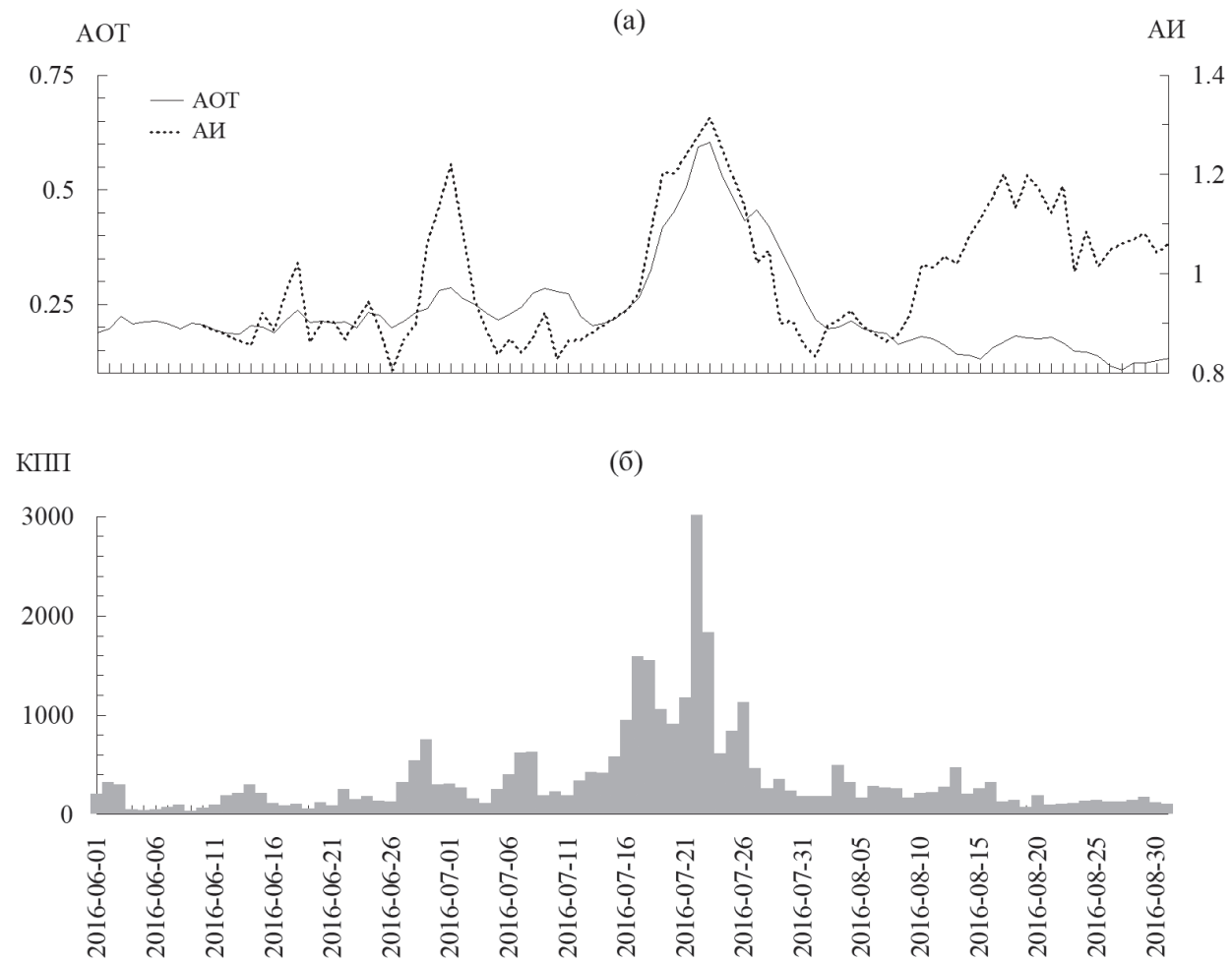

Рис. 4. Временные изменения летом 2016 г. средних величин АОТ (550 нм) и АИ над территорией $40^{\circ}-80^{\circ} \mathrm{N}$, $0^{\circ}-140^{\circ} \mathrm{E}(\mathrm{a})$ и суммарного количества пожарных пикселей (КПП) на указанной территории, в европейской части Евразии $\left(40^{\circ}-80^{\circ} \mathrm{N}, 0^{\circ}-60^{\circ} \mathrm{E}\right)$ и в Сибири $\left(40^{\circ}-80^{\circ} \mathrm{N}, 60^{\circ}-140^{\circ} \mathrm{E}\right)($ б).

Оптически плотные пылевые выносы наблюдались в районе пустыни Такла-Макан $\left(35^{\circ}-45^{\circ} \mathrm{N}\right.$, $75^{\circ}-95^{\circ}$ Е). Согласно нашим оценкам площадь распространения пыльной мглы достигала примерно 0.8 млн км². Крупномасштабные дымки (по-видимому, смоги и пылевые выносы) были замечены также на территории Индии и Пакистана $\left(25^{\circ}-35^{\circ} \mathrm{N}, 60^{\circ}-80^{\circ} \mathrm{E}\right)$ с суммарной площадью около 1 млн км².

Таким образом, в период с 15 по 31 июля 2016 г. крупномасштабные плотные дымки с МАОТ > 0.4 охватывали в Евразии территорию с площадью примерно 20 млн км².

Выполнен статистический анализ вариаций MAOT. На рис. 2 показана эмпирическая функция распределения МАОТ (1) и ее аппроксимация для МАОТ > 0.3. Указанная ЭФР с удовлетворительной точностью аппроксимируется (прямая 2 на рис. 2) соотношением (шаг по МАОТ равен 0.5$) w(\%)=14-7.4 \ln \tau_{\max }$ при условии $\tau_{\max }>0.3$, которое выполняется для территории площадью в 5000 «квадратных градусов».

Вероятность превышения МАОТ $=0.5$ составляет около $50 \%$, а вероятность превышения МАОТ $=1.0-$ примерно $25 \%$.

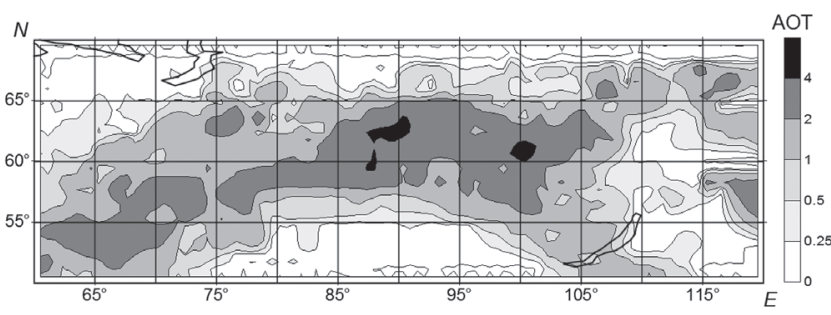

Рис. 5. Пространственное распределение средних значений аэрозольной оптической толщины для длины волны 550 нм на территории Сибири $\left(50^{\circ}-70^{\circ}, 60^{\circ}-120^{\circ} \mathrm{E}\right)$ в период 22-26.07.2016 г.

Следует отметить, что вероятности превышения МАОТ $=1.0$ для смогов на СКР и для пыльной мглы пустыни Такла-Макан оказались примерно равными $25 \%$.

\section{СИБИРСКАЯ ДЫМНАЯ МГЛА}

Сибирская дымная мгла летом 2016 г. в Евразии оказалась рекордной по площади распространения. Вариации АОТ и радиационные эффекты указанной СДМ на ЕЧР и прилегающих территориях в Европе рассмотрены в [31, 32, 42]. Очевидно (рис. 1), что максимальное радиационное воздействие ДА на атмосферу имело место 
на территории Сибири. Поэтому следует рассмотреть эффекты СДМ в Сибири и на территории Евразии в целом.

На рис. За показано пространственное распределение средних значений АОТ в период с 15 по 31 июля 2016 г. на охваченной задымлением части Евразии примерно от $40^{\circ}$ до $70^{\circ} \mathrm{N}$ и от $0^{\circ}$ до $140^{\circ}$ Е. Видно, что задымление Сибири было намного интенсивнее, чем задымление ЕЧР. Белыми контурами (рис. 3а) выделены области экстремальных значений (АОТ > 2.0), которые расположены, главным образом, в регионах с большими РМП.

Был выполнен статистический анализ вариаций АОТ на длине волны 550 нм для ограниченной координатами от $40^{\circ}$ до $70^{\circ} \mathrm{N}$ и от $0^{\circ}$ до $140^{\circ}$ Е территории за период с 15 по 31 июля 2016 г. Среднее значение АОТ для указанного ансамбля данных оказалось равным 0.51, стандартное отклонение -0.45 и максимальное АОТ - 2.39 (для пикселя с координатами $\left(61.5^{\circ} \mathrm{N}\right.$ и $\left.99.5^{\circ} \mathrm{E}\right)$.

В [43] было получено соотношение между коэффициентом рассеяния и фактором заполнения аэрозоля, которое было использовано нами $[11,40]$ для оценки массовой концентрации ДА в столбе атмосферы по данным значениям АОТ ( $\tau)$ на длине волны 550 нм: $\mathrm{M}=0.24 \tau$, где $\mathrm{M}$

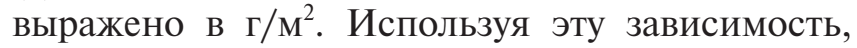
получим, что полная масса дымового аэрозоля в СДМ в среднем составляла примерно 3.2 млн т. Что касается массы дыма на территории западнее Урала, то она составляла примерно 1 млн т. По порядку величины она близка к массе дыма на ЕЧР летом 2010 г. (1.05 млн т) во время массовых лесных и лесоторфяных пожаров.

На рис. 4а представлен временной ход среднего значения АОТ (на территории, ограниченной координатами $40^{\circ}-80^{\circ} \mathrm{N}$ и $0^{\circ}-140^{\circ}$ Е для длины волны 550 нм летом 2016 г. Отчетливо выделяется период с большими значениями АОТ (до 0.6) во второй половине июля 2016 г., что согласуется по времени с максимальным количеством пожарных пикселей (рис. 4б).

С целью оценки уровня и масштабов задымления Сибири летом 2016 г. рассмотрим пространственное распределение АОТ на длине волны 550 нм на территории, ограниченной координатами $50^{\circ}-70^{\circ} \mathrm{N}$ и $60^{\circ}-120^{\circ} \mathrm{E}$, для 5 -дневного периода с 22 по 26 июля 2016 г., когда задымление Сибири было близко к максимуму (рис. 5). Видно, что на значительной части территории Сибири АОТ превышала 2.0 в отличие от среднего распределения АОТ на территории, ограниченной координатами $40^{\circ}-70^{\circ} \mathrm{N}$, $0^{\circ}-140^{\circ}$ Е (рис. 3а) в период с 15 по 31 июля 2016 г. В частности, обращает на себя внимание область интенсивного задымления южной части Западной Сибири, где в рассматриваемый период времени заметных пожаров не наблюдалось. Это явление можно объяснить эффектом увеличения АОТ при процессах перехода полулетучих органических соединений из газовой фазы в аэрозольную [26]. Отметим, что площадь территорий, занятых интенсивной дымной мглой c АОТ $>4.0$ оказалась сравнительно небольшой (рис. 5).

Была получена эмпирическая функция распределения АОТ (или т) для вышеуказанной территории Сибири в период с 22-26.07.2016 для пикселей с размерами $1^{\circ} \times 1^{\circ}$ с шагом $\Delta \tau=0.5$. Распределение $w(\tau)$, в отличие от ЭФР МАОТ оказалось экспоненциальным (для $\tau<4.0): w(\tau)=490 \exp \{-0.84 \tau\}$.

Вероятность превышения значений АОТ 0.5, 1.0 и 2.0 для рассматриваемого ансамбля данных составляют 59, 44 и 18\%. Среднее значение АОТ для охваченной задымлением территории Сибири оказалось равным 1.08, что соответствует суммарной массе дыма примерно 2 млн т.

При задымлении ЕЧР 5-9 августа 2010 г. на территории, ограниченной координатами $47^{\circ}-65^{\circ} \mathrm{N}$ и $25^{\circ}-55^{\circ} \mathrm{E}$, и при задымлении Сибири 27-31 августа 2012 г. (область задымления $51^{\circ}-70^{\circ} \mathrm{N}$ и $71^{\circ}-104^{\circ} \mathrm{E}$ ) средние значения АОТ были равны 1.05 и 1.02 , соответственно. Однако площади интенсивного задымления в 2010 и 2012 гг. были примерно в 2 раза меньше, чем в 2016 г. в Сибири.

\section{СМОГ НА СЕВЕРНОЙ КИТАЙСКОЙ РАВНИНЕ}

Наряду с СДМ летом 2016 г. наблюдался смог на Северной Китайской Равнине (СКР), которые нетрудно выявить по данным мониторинга АОТ на длине волны 550 нм. В данной работе анализировались вариации АОТ на территории, ограниченной координатами $25^{\circ}-45^{\circ} \mathrm{N}$ и $110^{\circ}-130^{\circ}$ Е. На рис. 6 показано пространственное распределение АОТ в период с 27 по 31 июля 2016 г. Максимальные уровни замутнения атмосферы в этот период времени наблюдались вблизи г. Пекин и в прибрежном районе Бохайского залива Желтого моря неда- 
леко от крупного порта Тяньцзин. Смещение максимумов АОТ от источников интенсивного аэрозольного загрязнения может быть обусловлено процессами «старения» аэрозоля в смоге, обусловленного процессами превращения газ-частица [23]. Отметим также, что в этот период времени смог охватил не только СКР, но и Корейский полуостров, а также значительные по площади морские акватории.

Выполнен статистический анализ вариаций АОТ в смоге. Среднее значение АОТ в рассматриваемый период времени составило 0.52. Вероятности превышения значений АОТ, равных 0.5 и 1.0, оказались равными 32 и $7.5 \%$ соответственно.

Получена ЭФР АОТ (с шагом $\Delta \tau=0.1$ ) для вышеуказанного смога (для пикселей $1^{\circ} \times 1^{\circ}$ ). Оказалось, что данная ЭФР с удовлетворительной точностью (для АОТ меньше 1.0 и больше 0.2) аппроксимируется линейной зависимостью $\lg w$ от АОТ или $\tau: \lg w=3.23-1.12 \tau$, что равносильно экспоненциальному распределению для $w$. Близкие к экспоненциальным ЭФР АОТ часто наблюдаются в условиях дымной мглы. Сравнение смога 22-26 июля 2016 г. с СДМ свидетельствует о том, что дымная мгла 2016 г. в Сибири была намного интенсивнее и масштабнее.

\section{ВАРИАЦИИ АЭРОЗОЛЬНОГО ИНДЕКСА В СИБИРСКОЙ ДЫМНОЙ МГЛЕ}

Согласно современным представлениям состав дымового аэрозоля при переносе воздушных масс существенно трансформируется, что приводит к изменениям его оптических и микрофизических характеристик («старение» аэрозоля [25-28]). Однако проследить указанные процессы с использованием существующих средств мониторинга довольно сложно. В частности, трудно получить количественную оценку эффекта увеличения АОТ [26] при дальнем переносе ДА. Поэтому важно обнаружить и оценить качественные изменения состава ДА при его «старении». Одним из возможных индикаторов трансформации ДА при дальнем переносе воздушных масс может служить так называемый аэрозольный индекс (АИ) [36, 37], который определяется через отношение $\eta$ интенсивностей $I$ уходящего излучения на двух длинах волн (331 и 360 нм) в ультрафиолетовой области спектpa: $\quad A И=100\left[\lg \eta_{\text {mes }}-\lg \eta_{\text {cal }}\right], \quad$ где $\eta=I_{360} / I_{331}$, а индексы mes и cal соответствуют данным из-

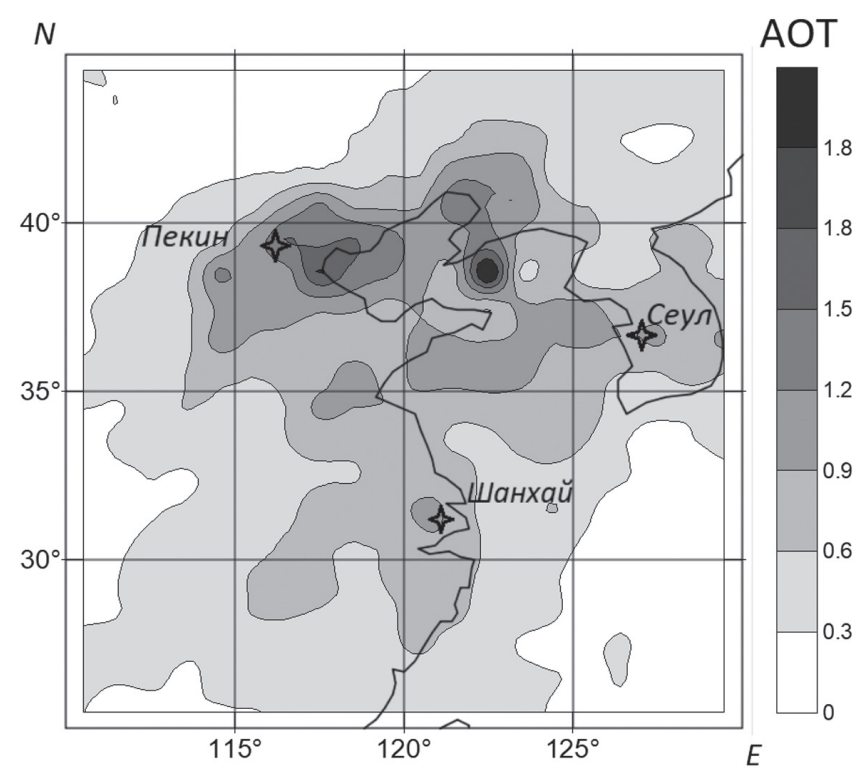

Рис. 6. Пространственное распределение в период 27-31 июля 2016 г. АОТ для длины волны 550 нм по данным спутникого спектрорадиометра MODIS/Aqua.

мерений и модельным данным. Используемая модель соответствует случаю чисто релеевской атмосферы. В настоящее время осушествляется мониторинг АИ с помощью установленного на спутнике Aura спектрометра OMI.

Пространственное распределение АИ на территории, ограниченной координатами $40^{\circ}-70^{\circ} \mathrm{N}$ и $0^{\circ}-140^{\circ} \mathrm{E}$, для периода времени с 15 по 31 июля 2016 г. представлено на рис. 3б. Нетрудно видеть, что в дымной мгле величина АИ меняется в широких пределах (светлой линией выделены области с АИ больше 2.5). Максимальным значениям АИ соответствуют области максимальных АОТ (рис. За) и положению лесных пожаров с большими РМП (рис. 3в). Отсюда, в частности, следует, что большим значениям АИ соответствует «свежий» дымовой аэрозоль. В удаленных от области интенсивных пожаров регионах, где наблюдается значительное уменьшение АОТ, среднее значение АИ для состарившегося ДА существенно уменьшается.

Как известно [37], большим значениям АИ соответствует большее поглощение аэрозоля. Следовательно, при дальнем переносе ДА происходит заметное уменьшение поглощательной способности аэрозоля, по-видимому не только в ультрафиолетовой области спектра. Это согласуется с результатами мониторинга альбедо однократного рассеяния (АОР) [42] во время заносов СДМ в период с 24 по 31 июля 2016 г. на станциях AERONET, расположенных в странах Европы, когда АОР часто превышает значения, 
типичные для ДА при пожарах в бореальных леcax, 0.94-0.96 («белый дым»).

О тесной связи АИ с АОТ в СДМ свидетельствуют результаты расчетов их временной изменчивости летом 2016 г. на территории в Евразии, ограниченной координатами $40^{\circ}-80^{\circ} \mathrm{N}$ и $0^{\circ}-140^{\circ} \mathrm{E}$ (рис. 4a): максимальные средние значения АИ (примерно до 1.3) наблюдались при больших средних значениях АОТ в СДМ.

В целом, по изменениям АИ в СДМ можно проследить, по крайней мере, на качественном уровне динамику трансформации состава ДА при его дальнем переносе.

Представляет интерес изменчивость АИ в летний сезон 2016 г. в целом, когда наблюдались максимумы в конце июня-начале июля и в августе.

\section{РАДИАЦИОННЫЕ ЭФФЕКТЫ ДЫМОВОГО АЭРОЗОЛЯ В ЕВРАЗИИ}

Возникающая при массовых пожарах в бореальных лесах дымная мгла существенно влияет на режимы переноса коротковолновой солнечной и тепловой радиации в атмосфере. Примерами здесь могут служить крупномасштабные задымления ЕЧР летом 2010 г. и Сибири в августе 2012 г. [10-12,40].

Сибирская дымная мгла 2016 г. радикально изменила радиационный режим атмосферы на огромной территории в Евразии. Об этом, в частности, свидетельствуют результаты оценки радиационных эффектов СДМ на ЕЧР 24 и 25 июля 2016 г. [31, 32], когда аэрозольные радиационные форсинги на верхней границе атмосферы были равны -29 Вт/м² в обоих случаях, а на нижней границе атмосферы -54 и $53 \mathrm{BT} / \mathrm{M}^{2}$ соответственно.

Анализ данных AERONET показал, что в задымленной атмосфере Сибири, ЕЧР и ряда стран Евразии, на которые в июле 2016 г. распространялась СДМ, дымовой аэрозоль оказался слабопоглощающим: АОР в задымленной атмосфере часто превышало 0.95-0.96. При этом в ДА преобладала тонкодисперсная фракция со сравнительно узким распределением частиц по размерам. В соответствии с результатами анализа характеристик ДА и данными мониторинга AOT MODIS/Terra на длине волны 550 нм с использованием радиационной модели ИФА были рассчитаны аэрозольные радиационные форсинги на верхней $\left(R_{1}\right)$ и нижней $\left(R_{2}\right)$ границах
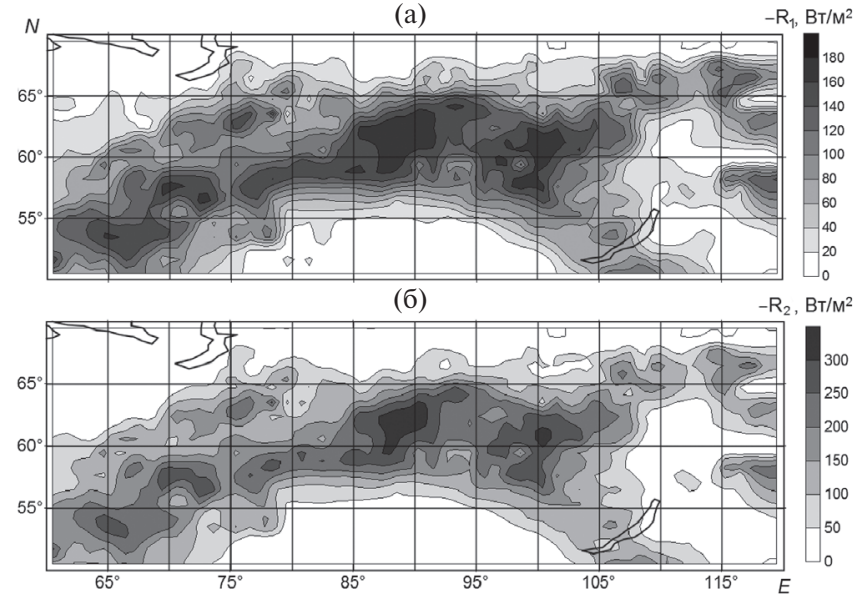

Рис. 7. Пространственное распределение среднего аэрозольного радиационного форсинга $-R_{1}$ (а) и $-R_{2}$ (б) на территории Сибири $\left(50^{\circ}-70^{\circ}, 60^{\circ}-120^{\circ}\right.$ Е) в период $22-26.07 .2016$ г.

атмосферы для периода времени с 22 по 26 июля 2016 г. на территории, ограниченной координатами $50^{\circ}-70^{\circ} \mathrm{N}$ и $60^{\circ}-120^{\circ}$ Е. Пространственные распределения аэрозольных радиационных форсингов представлены на рис. 7, где отчетливо выявляется тонкая структура пространственного распределения форсингов. Большие (по модулю) величины аэрозольных форсингов наблюдаются, во-первых, вблизи очагов интенсивных лесных пожаров. Отмеченное выше (рис. 5) повышение АОТ на юге Западной Сибири обусловило повышенные значения (по модулю) аэрозольных форсингов в этом регионе. На сложную структуру полей $R_{1}$ и $R_{2}$ повлияли, очевидно, как нестационарность процессов переноса, так и интенсивность пожаров.

Был выполнен статистический анализ вариаций $R_{1}$ и $R_{2}$ в рассматриваемый период времени. Среднее значение $R_{1}$ в период интенсивного задымления территории Сибири составило -67 Вт/м ${ }^{2}$, что заметно превышает (по модулю) значения средних аэрозольных форсингов $\left(R_{1}\right)$ в дымной мгле на ЕЧР 5-9 августа 2010 г. $\left(-61 \mathrm{BT} / \mathrm{M}^{2}\right)$ и в Сибири 27.07-31.072012 г. $\left(-54 \mathrm{BT} / \mathrm{M}^{2}\right)$. Что касается аэрозольного радиационного форсинга $R_{2}$ на верхней границе атмосферы, то в рассматриваемом случае он оказался равным -98 Вт/м ${ }^{2}$, что сравнимо со средним радиационным форсингом для дымной мглы в Сибири в период 27.07-31.07.2012 г. (-96 Вт/м²) и заметно меньше (по модулю) аэрозольного форсинга $R_{2}$ на ЕЧР 5-9 августа 2010 г. $(-110$ Вт/м²) Следует, однако, иметь в виду, что площадь задымленной территории Сибири в 2016 г. примерно в 2 раза превышала площади задымления на ЕЧР в 2010 г. и в Сибири в 2012 г. 
Были получены эмпирические функции распределения $R_{1}$ и $R_{2}$. В частности, ЭФР для $R_{1}$ с удовлетворительной точностью аппроксимируется степенной функцией (шаг $\Delta \lg \left|R_{1}\right|=0.2$ ), $w=9.6\left|R_{1}\right|^{0.65}$ при $\left|R_{1}\right|<180 \quad$ Вт/м². Вероятности превышения значений $\left|R_{1}\right|=20,50$ и $100 \mathrm{BT} / \mathrm{M}^{2}$ равны $70 \%, 53 \%$ и $27 \%$ соответственно.

Таким образом, в июле 2016 г. радиационные эффекты ДА на верхней и нижней границах атмосферы в Сибири оказались сравнимыми по величине с аэрозольными форсингами при задымления в Сибири летом 2012 г. и над ЕЧР летом 2010 г. и рекордными по площади территориями с сильными возмущениями радиационного режима.

\section{ЗАКЛЮЧЕНИЕ}

В работе показано, что в июле 2016 г. сибирская дымная мгла распространилась на территорию Евразии, превышающую 16 млн км², а вместе со смогами над Северной Китайской Равниной и прилегающими территориями, пылевыми выносами из пустыни Такла-Макан, a также с дымками на территории Индии и Пакистана охватила территорию около 20 млн км ${ }^{2}$.

Предложена методика диагностики оптически плотных дымок по распределению максимальных значений АОТ. Получена эмпирическая функция распределения МАОТ в период с 15 по 31 июля 2016 г. на территории Евразии. Показано, что ЭФР МАОТ аппроксимируется для МАОТ $>0.3$ линейной функцией логарифма MAOT.

Получено среднее пространственное распределение АОТ на длине волны 550 нм для периода времени 15-31 июля 2016 г. и территории $\left(40^{\circ}-70^{\circ} \mathrm{N}, 0^{\circ}-140^{\circ}\right.$ Е) и временная изменчивость АОТ летом 2016 г. в Евразии $\left(40^{\circ}-80^{\circ} \mathrm{N}, 0^{\circ}-140^{\circ} \mathrm{E}\right)$. Оценена суммарная масса дыма в сибирской дымной мгле (3.2 млн т). Охарактеризовано задымление Сибири $\left(50^{\circ}-70^{\circ} \mathrm{N}, 60^{\circ}-120^{\circ} \mathrm{E}\right)$ в период с 22 по 26.07.2016, когда среднее значение АОТ составляло 1.08 , а суммарная масса дыма достигала 2 млн т. Показано, что ЭФР АОТ в данном случае аппроксимируется экспоненциальной функцией АОТ.

Оценены масштабы замутнения атмосферы в смоге на СКР для периода времени 27-31 июля 2016 г., когда среднее значение АОТ составляло 0.52. Отмечено, что пространственные мас- штабы и интенсивность задымления в СДМ существенно превышали аналогичные параметры смога на СКР.

Представлено пространственное распределение аэрозольного индекса в СДМ (15-31 июля 2016 г.) на территории, ограниченной координатами $40^{\circ}-70^{\circ} \mathrm{N}, 0^{\circ}-140^{\circ} \mathrm{E}$, и временная изменчивость АИ летом 2016 г. $\left(40^{\circ}-80^{\circ} \mathrm{N}, 0^{\circ}-140^{\circ} \mathrm{E}\right)$. Показано, что качественный состав ДА, характеризуемый индексом АИ, меняется согласованно с количественной характеристикой аэрозоля (величина АОТ), что свидетельствует об изменении свойств аэрозоля при дальнем переносе задымленных воздушных масс.

Рассчитан форсинг дымового аэрозоля для коротковолновой солнечной радиации на верхней и нижней границах атмосферы в период с 22 по 26 июля 2016 г. на территории, ограниченной координатами $50^{\circ}-70^{\circ} \mathrm{N}$ и $60^{\circ}-120^{\circ} \mathrm{E}$. Средние значения аэрозольных форсингов на верхней и нижней границах атмосферы оказались равными -67 и -98 Вт/м². Показано, что средний аэрозольный форсинг на верхней границе атмосферы в период максимального задымления с 22 по 26 июля 2016 г. на территории Сибири $\left(50^{\circ}-70^{\circ} \mathrm{N}, 60^{\circ}-120^{\circ}\right.$ Е) превышал (по модулю) величины соответствующих форсингов при задымлении ЕЧР в 2010 г. и при задымлении Сибири в 2012 г. Получены ЭФР радиационных форсингов на верхней и нижней границах атмосферы. Показано, что ЭФР аэрозольного радиационного форсинга на верхней границе атмосферы с удовлетворительной точностью аппроксимируется степенной функцией.

В целом показано, что дымная мгла в июле 2016 г. была рекордной по пространственным масштабам, по массе дыма и по радиационному воздействию на атмосферу.

Благодарности. Авторы благодарят Г.С. Голицына за внимание к работе.

Источник финансирования. Работа выполнена в Федеральном государственном бюджетном учреждении науки Институте физики атмосферы им. А.М. Обухова РАН.

\section{СПИСОК ЛИТЕРАТУРЫ}

1. Голицын Г.С., Горчаков Г.И., Гречко Е.И., Семутникова Е.Г., Ракитин В.С., Фокеева Е.В., Карпов А.В., Курбатов Г.А., Байкова Е.С., Сафрыгина Т.П. Экстремальное загрязнение угарным газом погранич- 
ного слоя атмосферы в Московском регионе летом 2010 г. // ДАН. 2011. Т. 441. № 4. С. 532-538.

2. Еланский Н.Ф., Мохов И.И., Беликов И.Б., Березина Е.В., Елохов А. С., Иванов В.А., Панкратова Н.В., Постыляков О.В., Сафронов А.Н., Скороход А.И., Шумский Р.А. Газовые примеси в атмосфере над Москвой летом 2010 г. // Изв. РАН. Физика атмосферы и океана. 2011. Т. 47. № 6. C. 729-738.

3. Бондур В.Г., Гинзбург А.С. Эмиссия углеродсодержащих газов и аэрозолей от природных пожаров на территории России по данным космического мониторинга // ДАН. 2016. Т. 466. № 4. C. $473-477$.

4. Горчаков Г.И., Свириденков М.А, Семутникова Е.Г., Чубарова Н.Е., Холбен Б.Н., Смирнов А.В., Емиленко А.С., Исаков А.А., Копейкин В.М., Карпов А.В., Лезина Е.А., Задорожная О.С. Оптические и микрофизические характеристики аэрозоля задымленной атмосферы московского региона в 2010 г. // ДАН. 2011. Т. 437. № 5. C. 686-690.

5. Ситнов С.A. Оптическая толща аэрозоля и общее содержание оксида углерода над европейской территорией России в период массовых пожаров лета 2010 г.: взаимосвязь изменчивости загрязнений и метеорологических величин // Изв. РАН. Физика атмосферы и океана. 2011. Т. 47. № 6. C. 774-789.

6. Van Donkelaar A., Martin R.V., Levy R.C., da Silva M.A., Krzyzanowski M., Chubarova N.E., Semutnikova E.G., Cohen A.J. Satellite-based estimates of ground-level fine particle matter during extreme events: A case study of the Moscow fires in 2010 // Atmos. Environ. 2011. V. 45. P. 6225-6232.

7. Панченко М.В., Журавлева Т.Б., Козлов В.С., Насртдинов И.М., Полькин В.В., Терпугова С.А., Чернов Д.Г. Оценка радиационных эффектов аэрозоля в фоновых и задымленных условиях атмосферы Сибири на основе эмпирических данных // Метеорология и гидрология. 2016. № 2. C. $45-54$.

8. Аршинов М.Ю., Белан Б.Д. Исследования дисперсного состава аэрозоля в периоды весенней дымки и лесных пожаров // Оптика атмосферы и океана. 2011. Т. 24. № 6. С. 468-474.

9. Chubarova N., Nezval' Y., Sviridenkov M., Smirnov A., Slutsker I. Smoke aerosol and its radiative effects during extreme fire event over Central Russia in summer 2010 // Atmos. Meas. Tech. Discuss. 2011. V. 4. P. 6351-6386.

10. Мохов И.И., Горчакова И.А. Радиационный и температурный эффект летних пожаров 2002 г. в московском регионе // ДАН. 2005. Т. 400. № 4. C. 528-531.

11. Gorchakov G.I., Sitnov S.A., Sviridenkov M.A., Semoutnikova E.G., Emilenko A.S., Isakov A.A., Kopeikin V.M., Karpov A.V., Gorchkova I.A., Verichev K.S., Kurba- tov G.A., Ponomareva T.Ya. Satellite and ground based monitoring of smoke in the atmosphere during the summer wildfires in European Russia in 2010 and Siberia in 1212 // Int. J. Remote Sens. 2014. V. 35. № 15. P. 5698-5721.

12. Zhuravleva T.B., Kabanov D.M., Nasrtdinov I.M., Russkova T.V., Sakerin S.M., Smirnov A. and Holben B.N. Radiative characteristics of aerosol during extreme fire event over Siberia in summer 2012 // Atmos. Meas. Tech. 2017. № 10. Р. 179-198.

13. Горчакова И.А., Мохов И.И. Радиационный и температурный эффекты дымового аэрозоля в Московском регионе в период летних пожаров 2010 г. // Изв. РАН. Физика атмосферы и океана. 2012. Т. 48. № 5. С. 558-565.

14. Горчакова И.А., Мохов И.И., Аникин П.П., Емиленко A.C. Радиационный и температурный эффект длинноволнового поглощения дымового аэрозоля при пожарах в московском регионе летом 2010 г. // Изв. РАН. Физика атмосферы и океана. 2018. T. 54. № 2. С. 175-183.

15. Бондур В.Г. Космический мониторинг эмиссий малых газовых компонент и аэрозолей при природных пожарах в России // Исследование Земли из космоса. 2015. № 6. С. 21-25.

16.Горчаков Г.И., Аникин П.П, Волох А.А., Емиленко А.С., Исаков А.А., Копейкин В.М., Пономарева Т.Я., Семутникова Е.Г., Свириденков М.А., Шукуров K.A. Исследование состава задымленной атмосферы Москвы во время пожаров торфяников летом-осенью 2002 г. // Изв. РАН. Физика атмосферы и океана. 2004. Т. 40. № 3. C. 370-384.

17. Кузнецова И.Н., Звягинцев А.М., Семутникова Е.Г. Экологические последствия погодных аномалий летом 2010 года. Анализ условий аномальной погоды на территории России летом 2010 года // М.: Триада. 2010. С. 58-64.

18. Gorchakov G., Semoutnikova E., Karpov A., Lezina E. Air Pollution in Moscow Megacity // Advanced Topics in Environmental Health and Air Pollution Case Studies. Rijeka: Intech. 2011. P. 211-236.

19. Козлов В.С., Панченко М.В., Полькин В.В., Пхалагов Ю.А., Ужегов В.Н., Щелканов Н.Н., Яушева Е.П. Исследование особенностей динамики оптических и микрофизических характеристик аэрозоля в дымной мгле // Оптика атмосферы и океана 1999. Т. 12. № 5. С. 406-410.

20. Kozlov V.S., Yausheva E.P., Terpugova S.A., Panchenko M.V., Chernov D.G., Shmargunov V.P. Optical-microphysical properties of smoke haze from Siberian forest fires in summer 2012 / Int. J. Remote Sens. 2014. V. 35. № 15. P. 5722-5741.

21. Виноградова А.А., Смирнов Н.С., Коротков В.Н. Аномальные пожары 2010 и 2012 гг. на территории России и поступление черного углерода в Арктику // Оптика атмосферы и океана. 2016. Т. 29. № 6. C. 482-487. 
22. Горчаков Г.И., Васильев А.В., Веричев К.С., Семутникова Е.Г., Карпов А.В. Тонкодисперсный коричневый углерод в задымленной атмосфере // ДАН. 2016. T. 471. № 1. C. 91-97.

23. Seinfeld J.H., Pandis S.N. Atmospheric chemistry and physics. NY: Wiley Intersci. Publ. 1998. 1326p.

24. Konovalov I.B., Beekmann M., Berezin E.V., Petetin H., Mielonen T., Kuznetsova I.N., Andreae M.A. The role of semi-volatile organic compounds in the mesoscale evolution of biomass burning aerosol: a modeling case study of the 2010 mega-fire event in Russia // Atmos. Chem.. Phys. 2015. V. 15. P. 13269-13297.

25. Hobbs P.V., Sinha P., Yokelson R.E., Christian T.J., Blake D.R., Gao S., Kirchstetter T.W., Novakov T., Pilewskie P. Evolution of gases and particles from a savanna fire in South Africa // J. Geophys. Res. 2003. V. 108. № D13. SAF 21. P. 1-20.

26. Konovalov I.B., Beekmann M., Berezin E.V., Formenti P., Andreae M.O. Probing into the aging dynamics of biomass burning aerosol by using satellite measurements of aerosol optical depth and carbon monoxide // Atmos. Chem. Phys. 2017. V. 17. P. 4513-4537.

27. Abel S., Haywood J.M., Highwood E.J., Li J., Buseck P.R. Evolution of biomass burning aerosol properties from an agricultural fire in south Africa // Geophys. Res. Lett. 2003. V. 30. № 15. ASC1-4.

28. Vakkari V., Kerminen V.-M., Benkes J.P., Fiitta P., van Zyl P.G., Josipovic M., Venter A.D., Jars K., Worsnop D.P., Kulmala M., Loakso L. Rapid changes in biomass burning aerosols by atmospheric oxidation // Geophys. Res. Lett. 2014. V. 41. № 7. P. 2644-2651

29. Ситнов С.А., Мохов И.И., Горчаков Г.И. Связь задымления атмосферы европейской территории России летом 2016 года с лесными пожарами в Сибири и аномалиями атмосферной циркуляции // ДАН. 2017. Т. 472. № 4. С. 456-461.

30. Ситнов С.А., Мохов И.И., Горчаков Г.И., Джола A.B. Дымная мгла на европейской части России летом 2016 г.: связь с лесными пожарами в Сибири и аномалиями атмосферной циркуляции // Метеорология и Гидрология 2017. № 8. C. $50-63$.

31. Семутникова Е.Г., Горчаков Г.И., Ситнов С.А., Копейкин В.М., Карпов А.В., Горчакова И.А., Пономарева Т.Я., Исаков А.А., Гущин Р.А., Даценко О.И., Курбатов Г.А., Кузнецов Г.А. Сибирская дымная мгла над европейской территорией России в июле 2016 г. Загрязнение атмосферы и радиационные эффекты // Оптика атмосферы и океана. 2017. T. 30. № 11. C. 962-970.

32.Горчаков Г.И., Ситнов С.А., Семутникова Е.Г., Копейкин В.М., Карпов А.В., Горчакова И.А., Панкратова Н.В., Пономарева Т.Я., Кузнецов Г.А., Лоскутова О.В., Козловцева Е.А., Родина K.B. Крупномасштабное задымление ев- ропейской территории России и Белоруссии в июле 2016 г. // Исследование Земли из космоca. 2018. № 1. С. 1-16.

33. Levy R.C., Remer L.A., Mattoo S., Vermote E.F., Kaufman Y.J. Second-Generation Operational Algorithm: Retrieval of Aerosol Properties over Land from Inversion of Moderate Resolution Imaging Spectroradiometer Spectral Reflectance // Journal of Geophysical Research. 2007. V. 112. D13211.

34. Acker J.C., Leptoukh G. Online Analysis Enhances Use of NASA Earth Science Data // Eos, Transactions, American Geophysical Union. 2007. V. 88. P. 14-17.

35. Justice C.O., Giglio L., Korontzi S., Owens J., Morrisette J.T., Roy D., Descloitres J., Alleaume S., Petitcolin F., Kaufman $Y$. The MODIS Fire Products // Remote Sensing of Environement. 2002. V. 83. P. 244-262.

36. Levelt P.F., van den Oord G.H.J., Dobber M.R. et al. The Ozone Monitoring Instrument // IEEE Trans. Geosci. Remote Sens. 2006. V. 44. № 5. P. 1093-1101.

37. Torres O., Bhartia P.K. Impact of tropospheric aerosol absorption on ozone retrieval from backscattered ultraviolet measurements // J. Geophys. Res. 1999. V. 104. № D17. P. 21569-21577.

38. Holben B.N., Eck T.F., Slutsker I., Tanre D., Buis J.P., Setzer A., Vermote E., Reagan J.A., Kaufman Y.J., Nakajima N., Lavenu F., Jankowiak I., Smirnov A. AERONET - A federated instrument network and data archive for aerosol characterization // Remote Sens. Environ. 1998. V. 66. P. 1-16.

39. Gorchakov G..I., Golitsyn G..S., Sitnov S.A., Karpov A.V., Gorchakova I.A., Gushchin R.A., Datsenko O.I. Large-Scale Haze over Eurasia in July 2016 // Doklady Earth Sciences. 2018. V. 482. № 1. P. 1212-1215.

40. Sitnov S.A., Gorchakov G.I., Sviridenkov M.A., Kopeikin V.M., Ponomareva T.Ya., Karpov A.V. The effect of atmospheric circulation on the evolution and radiative forcing of smoke aerosol over European Russia during the summer of $2010 / /$ Izv. Atmos. Ocean. Phys. 2013. V. 49. № 9. Р. 1006-1018.

41. Бондур В.Г. Космический мониторинг природных пожаров в России в условиях аномальной жары 2010 г. // Исслед. Земли из космоса. 2011. № 3. C. 3-13.

42. Горчаков Г.И., Карпов А.В., Копейкин В.Н., Горчакова И.А., Гущин Р.А., Даценко О.И. Пономарёва T.Я. Сибирская дымная мгла над Европой в июле 2016 г. // Оптика атмосферы и океана. Физика атмосферы: Тезисы докладов XXIV Международного симпозиума. Томск: Изд-во ИОА СО PAH. 2018. - 216 c. C. 21. ISBN 978-5-94458-171-6. http://symp.iao.ru/ru/aoo/24/progpdf.

43. Горчаков Г.И., Емиленко А.С., Свириденков М.А. Однопараметрическая модель приземного аэрозоля // Изв. АН СССР. Физика атмосферы и океана. 1981. T. 17. № 1. С. 39-49. 


\title{
Eurasia Large-scale Hazes in Summer 2016
}

\author{
G. I. Gorchakov ${ }^{1}$, S. A. Sitnov ${ }^{1}$, A. V. Karpov ${ }^{1}$, I. A. Gorchakova ${ }^{1}$, \\ R. A. Gushchin ${ }^{1,2}$, O. I. Datsenko ${ }^{1,2}$ \\ ${ }^{1}$ Obukhov Institute of Atmospheric Physics, RAS \\ Pyzhevsky per., 3, Moscow 109017, Russia \\ ${ }^{2}$ MIREA - Russian Technological University \\ Vernadsky Avenue 78, Moscow 119454, Russia \\ e-mail: gengor@ifaran.ru
}

Received: 31.07.2018

Accepted: 28.11.2018

\begin{abstract}
Using maximum aerosol optical depth (MAOD) spatial distribution formation technique the optically dense haze expansion scales in period from 15 to 31 July 2016 over Eurasia are estimated in during great Siberian smoke haze (SSH) with the area $16 \mathrm{mln} \mathrm{km}^{2}$ about, smog over the Northern China Plain $\left(2 \mathrm{mln} \mathrm{km}^{2}\right)$, dust haze in Takla Makan desert $\left(0.8 \mathrm{mln} \mathrm{km}^{2}\right)$ and hazes in India and Pakistan $\left(1 \mathrm{mln} \mathrm{km}^{2}\right.$ approximately). Empirical distribution function (EDF) MAOD is received which is approximated by linear function of MAOD logarithm. Aerosol optical depth (AOD) spatial distribution at wavelength $550 \mathrm{~nm}$ in $\mathrm{SSH}$ is analyzed. Total smoke aerosol mass assessment in SSH (3.2 mln tons) is evaluated. Smoke aerosol (SA) mass during maximum growth period from 22 July to 26 July 2016 over Siberia $\left(50^{\circ}-70^{\circ}, 60^{\circ}-120^{\circ} \mathrm{E}\right)$ was equal $2 \mathrm{mln}$ tons approximately. Aerosol index (AI) temporal variability is illustrated visually SA composition qualitative change in SSH during long-range transport. It is shown that AI variations are correlated with AOD variations. Aerosol radiative forcing (ARF) at the top and the bottom of the atmosphere over Siberia from 22 July to 26 July 2016 is estimated (average ARF are equal -68 and $-98 \mathrm{~W} / \mathrm{m}^{2}$ ). EDF AOD and EDF ARF at the top of the atmosphere are approximated by exponential and power function of AOD correspondingly.
\end{abstract}

Keywords: large-scale optically dense hazes, dense haze diagnosis method, long-range transport, Siberian smoke haze, mass forest fires, active forest fires, fire radiative power, smoke aerosol, aerosol optical depth, empirical distribution function, smoke mass, aerosol index, aerosol radiative forcing, MODIS, AERONET. 